- Departamento de Cirurgia de Cabeça e Pescoço, Instituto do Câncer Arnaldo Vieira de Carvalho (ICAVC), São Paulo, SP, Brasil
Correspondence to:

Rafael De Cicco

Departamento de Cirurgia de Cabeça e Pescoço

Instituto do Câncer Arnaldo Vieira de Carvalho

Rua Dr. Cesário Motta Júnior, 112 01219-010 - São Paulo, SP, Brasil

rafaeldecicco@gmail.com

Received on Apr/13/2021 Accepted on July/21/2021

DOI: 10.20945/2359-3997000000411

\section{Radiofrequency ablation of thyroid nodules: prospective cost-effectiveness analysis in comparison to conventional thyroidectomy}

\author{
Marcelo Soares Schalch ${ }^{1}$ \\ https://orcid. org/0000-0002-8318-4663 \\ Anna Carolina Novais Costa ${ }^{1}$ \\ https://orcid.org/0000-0002-3544-406 \\ Rafael Pereira de Souza ${ }^{1}$ \\ https://orcid org/0000-0001-5916-9730 \\ Filipe Lamounier Barros Guerra' \\ https://orcid.org/0000-0003-2187-106X \\ Roberta Guerreiro' \\ https://orcid.org/0000-0002-8219-3058 \\ Rafael De Cicco' \\ https://orcid.org/0000-0003-2505-0461
}

\begin{abstract}
Objective: The objective of this study is to compare the total costs of surgery and radiofrequency (RF) ablation for the treatment of benign thyroid nodules. Materials and methods: This is a prospective randomized study comparing cases treated with US-guided RF ablation (cases) and surgery (control). They were selected and allocated to groups (thyroidectomy or radioablation) by permuted block randomization in blocks of five cases each. Results: Five cases of RF Ablation were compared with five cases of thyroidectomies conducted in the same period. Similar complication rates were observed in both groups. Shorter operating time and hospital stay were observed for the RF group. In the evaluation of the total cost between procedures, radioblation represented $76 \%$ of the cost of partial thyroidectomy. Conclusion: This study demonstrated that radioablation has a competitive cost, making it an effective alternative in the treatment of benign thyroid nodules. Arch Endocrinol Metab. 2021;65(6):752-7
\end{abstract}

\section{Keywords}

Radiofrequency ablation; partial thyroidectomy; thyroid nodule

\section{INTRODUCTION}

$\mathrm{T}$ hyroid nodules are a common finding in clinical practice (1). The prevalence of thyroid nodules identified by palpation alone on physical examination varies from $4 \%$ to $7 \%$, whereas autopsy studies identified a prevalence of clinically nonpalpable nodules of up to $65 \%(2,3)$. With the advancement of imaging tests, including ultrasound, tomography, nuclear magnetic resonance and positron emission scanning (PET-CT), it has become more common to identify previously undiagnosed nodules $(4,5)$. Ultrasound (US) can detect clinically nonpalpable nodules in $20 \%$ to $76 \%$ of the adult population $(6,7)$.
With the emergence and increased availability of and access to US, we have observed an increase in the identification and diagnosis of thyroid nodules. As a result, the challenge of finding the best treatment with the lowest number of complications and sequelae for the patient that is also economically viable has arisen.

The current indications for the treatment of benign thyroid nodules, according to the guidelines of the American Thyroid Association (ATA) (8), include bulky nodules larger than $4 \mathrm{~cm}$ in diameter that cause both compressive and aesthetic symptoms. The patient's desires regarding the treatment modality should also be taken into account (9). 
The treatments that were commonly used over the last decades were surgery, hormone suppression or clinical observation. Surgical treatment is associated with some complications, such as recurrent laryngeal nerve injury and its consequences $(0.3 \%$ to $1.7 \%)$, hypoparathyroidism with permanent hypocalcemia (1.3\% to $3 \%$ ), permanent scarring of the neck and hypothyroidism, which occurs in $5 \%$ to $49 \%$ of lobectomy cases and $100 \%$ of total thyroidectomy cases $(3,10,11)$. Although such complications are rare in procedures performed by high-volume surgeons, they cannot be neglected. With this therapeutic modality, there is also the fear of possible cervical hematoma, severe complications and the need for additional surgery. There is also a need for hospitalization and general anesthesia $(7,12)$. Another option is clinical treatment with hormonal suppression; however, the efficacy of this treatment is controversial, and there is no evidence of obvious effects on nodule growth inhibition or size reduction $(7,12)$.

Ablation with ethanol for the treatment of benign thyroid nodules was also effective but is associated with high recurrence rates ( $5 \%$ to $25 \%$ ) (13-15); it is indicated mainly for predominantly cystic nodules, since the solid components are considered more resistant to diffusion and the vascularization of solid nodules favors ethanol drainage, thus limiting the success of the procedure in predominantly solid nodules (16).

Clinical observation in patients with large, symptomatic and predominantly solid thyroid nodules carries the probability that the nodule will progress and the symptoms will worsen, in addition to not providing relief for the already present symptoms.

The desire to avoid the anterior neck scar has led to the development of remote-access thyroidectomy techniques, which have surgical complication rates that are the same as those of conventional surgery. However, this surgical method depends on the location and size of the thyroid nodules, and not all nodules are suitable for this type of treatment $(17,18)$.

More recently, radiofrequency (RF) ablation has emerged as a minimally invasive method that preserves thyroid function and offers satisfactory results in terms of thyroid nodule volume reduction and without recurrence or the need for additional surgery (19).

Like most medical innovations, its cost should be taken into account, and high costs may be a barrier to the implementation of RF, especially in developing countries such as Brazil. However, there are no data in the literature that support this concern, nor are there studies that compare the costs and effectiveness of surgery versus RF ablation.

\section{MATERIALS AND METHODS}

The objective of this study is to compare the total costs of surgery and RF ablation for the treatment of benign thyroid nodules.

This is a prospective randomized study comparing cases treated with US-guided RF ablation (cases) and surgery (control). Patients from the Department of Head and Neck Surgery of Arnaldo Vieira de Carvalho Cancer Institute (ICAVC, for its acronym in Portuguese) were selected and allocated to groups (thyroidectomy or radioablation) by permuted block randomization in blocks of five cases each.

This study was approved by the research ethics committee of Arnaldo Vieira de Carvalho Cancer Institute (CAAE $\mathrm{n}^{\mathrm{o}}$ 19516619.2.0000.5471). Only patients with thyroid nodules with benign cytology prior to treatment were included in the study. The inclusion criteria were patients with thyroid nodules diagnosed as benign with fine-needle aspiration biopsy (FNAB) according to the Bethesda classification (8); predominantly solid $(>50 \%)$ thyroid nodules on US; nodules larger than $3 \mathrm{~cm}$; nodules causing aesthetic problems or compressive symptoms; and the desire to receive treatment.

The exclusion criteria were the presence of nodules that were indeterminate or suspicious for malignancy; nodules that were smaller than $3 \mathrm{~cm}$ and asymptomatic; clinical comorbidities that contraindicated surgery; and patient refusal to participate in the study. After randomization, the patients were informed about the proposed treatment for their group and completed the informed consent form. No patient refused the proposed treatment.

The variables collected related to the patient (sex, age, comorbidities), disease (nodule size at $0,30,60$ and 90 days) and cost (operating room time and procedure duration, length of hospital stay, total hospital cost, type of anesthesia and cost of materials used).

To perform the cost analysis, the actual cost tables of our service (ICAVC) were used. These include the costs of daily stays, medications, surgery, pathology and materials adjusted according to the month of the procedure. For standardization, the SIMPRO table (materials and medications) number 128 , in circulation 
in June/July 2020, was used. The cost of procedures and doctor's fees were calculated according to the cost table of the Hierarchical Brazilian Classification of Medical Procedures (CBHPM, for its acronym in Portuguese; $5^{\text {th }}$ edition). In addition, the cost of special materials for RF ablation treatment were established by the manufacturer and supplier of Surgical Line ${ }^{\circledR}$ equipment.

Descriptive statistical analyses were performed. Additionally, comparisons between the groups were made using the chi-square test for categorical variables and Student's t-test for continuous variables.

\section{RESULTS}

The mean age of the patients in both groups was 46.4 years, with no significant difference between groups $(\mathrm{p}=0.79)$. All patients in this study were female, which increased the homogeneity of the groups (Table 1).

The most frequently observed comorbidity was systemic arterial hypertension, which affected four of the five patients in the case group and one patient in the control group. This was followed by asthma, which affected one patient in the case group and two in the control group.

Regarding preoperative symptoms, compressive symptoms were present in one patient in each group, and all other patients were asymptomatic.
The two groups differed widely in operating room time. The RF ablation group had a mean procedure duration of 71.4 minutes, ranging from 40 to 118 . In the partial thyroidectomy group, the surgery time ranged from 60 to 120 minutes, with a mean of 90 minutes. $\mathrm{RF}$ ablation resulted in a $20.6 \%$ reduction in operating room time $(\mathrm{p}=0.01)$. The mean length of hospital stay in the RF ablation group was significantly lower (17.6 hours) than that of the thyroidectomy group (26.2 hours) $(\mathrm{p}=0.01)$ (Table 1 , Figure 1$)$. There was no need for hospital stay in the case group. It is important to emphasize, however, that admission in our service is routinely performed the night before procedure. This

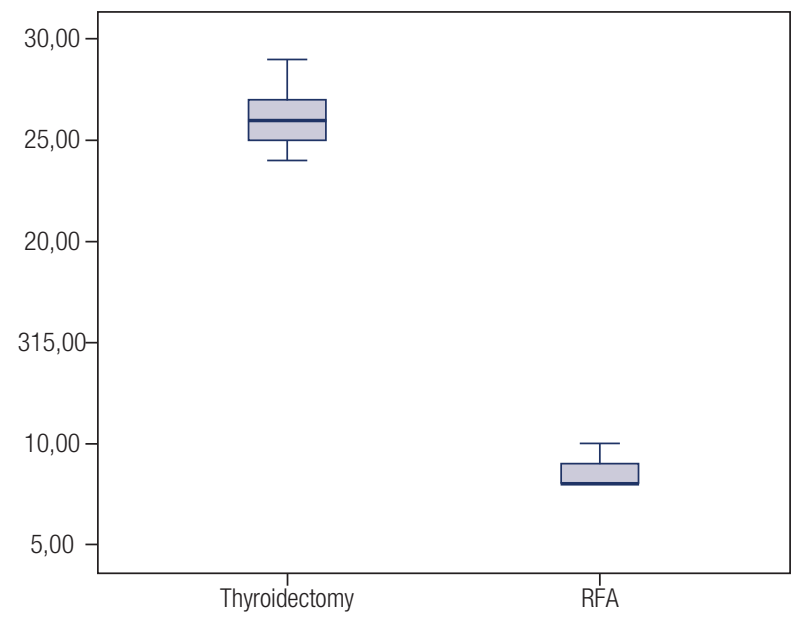

Figure 1. Length of hospital stay (hours) for each group.

Table 1. Distribution of the variables by group

\begin{tabular}{|c|c|c|c|}
\hline Variables & Thyroidectomy & Radiofrequency Ablation & $\mathbf{p}$ \\
\hline Age & 47.6 & 45.2 & 0.79 \\
\hline \multicolumn{4}{|l|}{ Gender } \\
\hline Operation time - mean & 90 & 71.4 & 0.29 \\
\hline Operating room time - mean & 172 & 90 & 0.01 \\
\hline \multicolumn{4}{|l|}{ Complications } \\
\hline No & 3 & 3 & \multirow{3}{*}{0.51} \\
\hline Edema & 2 & 1 & \\
\hline Vocal cod palsy & 0 & 1 & \\
\hline Nodule diameter - mean & 39.4 & 40.6 & 0.72 \\
\hline Fine needle aspiration biopsy & \| (100\%) & \| (100\%) & \\
\hline Hospital stay - hours & 26.2 & 8.6 & 0.01 \\
\hline Cost of material - charged by hospital & 416.69 & 225.42 & 0.01 \\
\hline Cost of material - SIMPRO & 2137.93 & 1419.11 & 0.02 \\
\hline Cost of hospital stay - charged by hospital & 667 & 171.99 & 0.01 \\
\hline Cost of hospital stay - SIMPRO & 413.74 & 146.27 & 0.01 \\
\hline Medical costs - CBHPM & 1273.66 & 1070 & 0.01 \\
\hline Total cost CBHPM + SIMPRO & 3825.33 & 2661.1 & 0.007 \\
\hline
\end{tabular}


practice ensures floor vacancy for the patient to undergo the procedure. In the RF group, three patients $(60 \%)$ were hospitalized the night before, while in the partial thyroidectomy group, four (80\%) were hospitalized the day before. This practice resulted in an overall increase in length of hospital stay in both groups.

The mean nodule size in the RF ablation group was $37.57 \mathrm{~mm}$, whereas in the thyroidectomy group, it was $39.4 \mathrm{~mm}$; the FNAB findings for all nodules were as benign according to the Bethesda classification (Table 1 ).

In the RF ablation group, $60 \%$ of patients had no postoperative complaints, and the same proportion experienced no complications. One patient (20\%) complained of neck "swelling" and the postoperative complication of local edema, one patient (20\%) complained of paresthesia in the right arm, and one patient $(20 \%)$ developed a nonexpanding and nonpulsatile hematoma. All complications were selflimited and conservatively treated, and none resulted in prolonged hospitalization.

In the thyroidectomy group (surgical), 60\% had no complaints during the postoperative period. One patient presented with hoarseness and unilateral vocal fold paralysis, and one patient complained of "weak voice at the end of day". All complications were selflimited, did not require prolonged hospitalization and were treated conservatively.

None of the patients had symptoms of hypoparathyroidism, and none of those who underwent PTH testing during the postoperative period had a PTH level lower than $27 \mathrm{pg}$.

To ensure adequate standardization, we used the CBHPM and SIMPRO tables. The patients in the RF ablation group did not require daily hospitalization and had a total hospital cost of R\$ 146.27 per patient based on the CBHPM table. In contrast, the average hospitalization cost of the thyroidectomy group (also based on the CBHPM table) was 2.82 times higher ( $\mathrm{p}=$ 0.01 ), totaling R\$ 413.74 per patient (Table 1, Figure 2).

A difference was also found in the cost of materials and medications. According to the SIMPRO table, the average cost of RF ablation was R 1,419.11, while for thyroidectomy, it was R $2,137.93$, which was 1.50 times higher $(\mathrm{p}=0.02)$. The cost difference regarding medications is mainly justified by the fact that RF ablation group underwent procedure under sedation and local anesthesia, while the partial thyroidectomy group underwent general anesthesia. When the costs of orthoses, prostheses and special materials (OPSM)

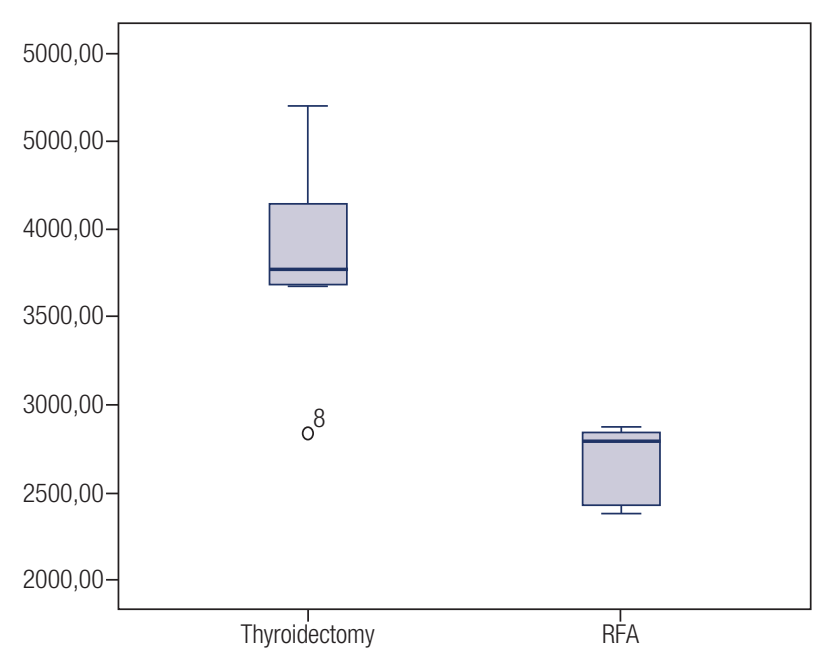

Figure 2. Standardized costs of materials and medications (CBHPM/ SIMPRO).

[intraoperative nerve monitoring - R\$ 14,500.00; harmonic shears - $\mathrm{R} \$ 5,634.36$; radiofrequency ablation needles - R\$ 7,000.00; the cost of radiofrequency ablation needles was determined by the supplier (Surgical Line ${ }^{\circledR}$ ), and that of the other materials was based on the SIMPRO table] were included, the average total cost of materials for patients in the RF ablation group was R $8,419.11$, while for the thyroidectomy group, it was R\$10,137.93. Although we do not use OPSM in our service, we decided to add the cost, once we believe this material is widely used in practice, in our country, among private and even public hospitals.

Pathology/freezing cost of RS 0 for patients undergoing RF ablation since there were no anatomicalpathological specimens, while in the control group, this cost averaged R\$ 344.16 per patient (Table 1).

Finally, according to the CBHPM table, doctors' fees also cost less for the RF ablation group ( $\$ 1,070)$ than for the thyroidectomy group (R $\$ 1,273.66$ ), which had a cost that was 1.19 times higher $(\mathrm{p}=0.01)$.

When all costs were summed, it was determined that the cost of RF ablation was $40 \%$ of the cost of partial thyroidectomy. The average cost of R\$ 9,661.10 per RF ablation patient was lower than the average cost of R\$ 23,959.69 per patient undergoing thyroidectomy. In addition, the actual costs paid by the institution also differed between the procedures.

\section{DISCUSSION}

RF ablation of thyroid nodules is a relatively new procedure (19). It is a minimally invasive treatment 
that has been shown to be effective and to have a low risk of complications. This therapeutic modality has the advantage of being minimally invasive, effective, safe, economical and aesthetically satisfactory, which enables early recovery of a normal lifestyle and work activity in addition to having a lower rate of complications. This modality preserves thyroid function in most cases, and the rate of RF ablation patients who later require surgery to control symptoms was zero in a recent study (7).

The efficacy of RF ablation was demonstrated not only by the absence of clinical problems but also by the reduction in volume that was observed on US at the 6-month follow-up after the procedure. RF ablation is effective for nonfunctioning, autonomous or malignant thyroid nodules, regardless of their solid component (20-22).

According to Jeong and cols. (21), the reduction in the mean volume of 140 nonfunctioning thyroid nodules observed at the 6-month follow-up was $84.79 \%$ after one or more than two RF ablation sessions (mean $=1.4$ ). When the nodules were grouped into mainly cystic, mixed and mainly solid nodules, the volume reduction was significantly greater for the solid nodules than for the other types at the 1-month follow-up. However, at the 6-month follow-up, there was no significant difference in volume reduction among the three types. Tang and cols. (3) observed a complete ablation rate of thyroid nodules of $98.95 \%$ with RF.

Regarding thyroid function, cases of hypothyroidism after RF ablation have been reported. The cause of hypothyroidism is not yet clear (23-26). Some studies have reported transient or permanent hypothyroidism in some patients after RF ablation. Although thyroid function seems to only rarely be influenced by RF ablation, it is not clear whether RF ablation affects thyroid function in patients with bilateral benign thyroid nodules.

Thus, the use of US-guided percutaneous RF ablation to treat benign thyroid nodules has the advantages of definitive efficacy, significant reduction of lesion volume, high nodule regression rate, reduced damage to the surrounding normal tissue and a low complication rate (most complications are reversible and temporary). There is no surgical incision, and the method can maximally satisfy patients' aesthetic demands; therefore, RF ablation offers an adequate first-choice treatment for benign thyroid nodules and, in some cases, it can replace surgery as a treatment for benign thyroid nodules.
The debate on the viability of RF ablation as a therapeutic option for thyroid nodules reflects concerns about the increased cost of this modality compared to the current gold standard treatment, especially in developing countries such as Brazil. However, our study demonstrated good cost-effectiveness in the case group, with the RF ablation representing 81\% of the cost of the current gold-standard treatment. We cannot disregard the cost of the device, which is $\mathrm{R} \$ 7,000.00$, according to the distributor. This is higher than the total hospital cost of both studied procedures, according to the referenced tables. However, we also cannot disregard the fact that most thyroidectomies, especially those performed in the context of private health insurance, currently use high-cost materials such as nerve monitoring systems, hemostats and harmonic shears, the costs of which were included in the results of the study.

The standard treatment for benign thyroid nodules is surgical, in the form of partial or total thyroidectomy. This treatment has great therapeutic efficacy, offers the possibility of evaluating the specimen anatomically and pathologically and is well accepted by the medical community. However, it is not without complications.

The RF ablation technique, which was recently introduced for the treatment of thyroid nodules, offers the advantages of not requiring general anesthesia, early hospital discharge and absence of a neck scar, with well-established results. Furthermore, the use of US-guided percutaneous RF ablation to treat benign thyroid nodules not only has the advantages of definitive efficacy, significant reduction of lesion volume, high nodule regression rate, reduced damage to surrounding normal tissue and a low rate of complications but also lower costs than surgical treatment. Thus, RF may be adequate as the treatment of choice for benign thyroid nodules and, in some cases, may replace the surgical treatment of benign thyroid nodules.

In conclusions, the study showed that despite being a newly incorporated technology, RF ablation has a competitive cost, making it an effective option for the treatment of benign thyroid nodules.

Contributor statements: Marcelo S. Schalch designed the study, wrote the protocol, drafted the article, and interpreted the data. Anna Carolina N. Costa designed the study and wrote the protocol. Rafael P. Souza, Filipe L. B. Guerra and Roberta Guerreiro participated in the study design and was responsible for the final approval of this version and Rafael De Cicco conducted the statistical analysis and reviewed studies. 
Acknowledgments: the authors would like to thank Arnaldo Vieira de Carvalho Cancer Institute.

Disclosure: the authors declare that the research was conducted in the absence of any commercial or financial relationships that could be construed as a potential conflict of interest.

\section{REFERENCES}

1. Tan GH, Gharib H. Thyroid incidentalomas: Management approaches to nonpalpable nodules discovered incidentally on thyroid imaging. Ann Intern Med. 1997;126(3):226-31.

2. Singer PA, Cooper DS, Daniels GH, Ladenson PW, Greenspan FS, Levy EG, et al. Treatment guidelines for patients with thyroid nodules and well-differentiated thyroid cancer Arch Intern Med. 1996;156(19):2165-72.

3. Tang X, Cui D, Chi J, Wang Z, Wang T, Zhai B, et al. Evaluation of the safety and efficacy of radiofrequency ablation for treating benign thyroid nodules. J Cancer. 2017;8(5):754-60.

4. Guth S, Theune U, Aberle J, Galach A, Bamberger CM. Very high prevalence of thyroid nodules detected by high frequency (13 $\mathrm{MHz}$ ) ultrasound examination. Eur J Clin Invest. 2009;39(8):699706.

5. Smith-Bindman R, Miglioretti DL, Johnson E, Lee C, Feigelson HS, Flynn $M$, et al. Use of diagnostic imaging studies and associated radiation exposure for patients enrolled in large integrated health care systems, 1996-2010. JAMA. 2012;307(22):2400-9.

6. Bennedbæk FN, Hegedüs L. Treatment of Recurrent Thyroid Cysts with Ethanol: A Randomized Double-Blind Controlled Trial. J Clin Endocrinol Metab. 2003;88(12):5773-7.

7. Ji Hong M, Baek JH, Choi YJ, Lee JH, Lim HK, Shong YK, et al. Radiofrequency ablation is a thyroid function-preserving treatment for patients with bilateral benign thyroid nodules. $J$ Vasc Interv Radiol. 2015;26(1):55-61.

8. Haugen BR, Alexander EK, Bible KC, Doherty GM, Mandel SJ, Nikiforov YE, et al. 2015 American Thyroid Association Management Guidelines for Adult Patients with Thyroid Nodules and Differentiated Thyroid Cancer: The American Thyroid Association Guidelines Task Force on Thyroid Nodules and Differentiated Thyroid Cancer. Thyroid. 2016;26(1):1-133.

9. Stagnaro-Green A, Abalovich M, Alexander E, Azizi F, Mestman J, Negro R, Nixon A, Pearce EN, Soldin OP, Sullivan S, Wiersinga W; American Thyroid Association Taskforce on Thyroid Disease During Pregnancy and Postpartum. Guidelines of the American Thyroid Association for the diagnosis and management of thyroid disease during pregnancy and postpartum. Thyroid. 2011 Oct;21(10):1081-125.

10. Bron LP, O'Brien CJ. Total thyroidectomy for clinically benign disease of the thyroid gland. Br J Surg. 2004;91(5):569-74.

11. Ozbas S, Kocak S, Aydintug S, Cakmak A, Demirkiran MA, Wishart GC. Comparison of the complications of subtotal, near total and total thyroidectomy in the surgical management of multinodular goitre. Endocr J. 2005;52(2):199-205.
12. Delbridge L, Guinea Al, ReeveTS. Total thyroidectomy for bilateral benign multinodular goiter: Effect of changing practice. Arch Surg. 1999;134(12):1389-93.

13. Hegedüs L, Bonnema SJ, Bennedbæk FN. Management of simple nodular goiter: Current status and future perspectives. Endocr Rev. 2003;24(1):102-32.

14. Del Prete S, Caraglia M, Russo D, Vitale G, Giuberti G, Marra M, et al. Percutaneous ethanol injection efficacy in the treatment of large symptomatic thyroid cystic nodules:Ten-year follow-up of a large series. Thyroid. 2002;12(9):815-21.

15. Lee JH, Kim YS, Lee D, Choi H, Yoo H, Baek JH. Radiofrequency ablation (RFA) of benign thyroid nodules in patients with incompletely resolved clinical problems after ethanol ablation (EA). World J Surg. 2010;34(7):1488-93.

16. Kim JH, Lee HK, Lee JH, Ahn IM, Choi CG. Efficacy of sonographically guided percutaneous ethanol injection for treatment of thyroid cysts versus solid thyroid nodules. Am J Roentgenol. 2003;180(6):1723-6.

17. Karakas E, SteinfeldtT, Gockel A, SchlosshauerT, Dietz C, Jäger J, et al. Transoral thyroid and parathyroid surgery - Development of a new transoral technique. Surgery. 2011;150(1):108-15.

18. Materazzi G, Fregoli L, Manzini G, Baggiani A, Miccoli M, Miccoli P. Cosmetic result and overall satisfaction after minimally invasive video-assisted thyroidectomy (MIVAT) versus robot-assisted transaxillary thyroidectomy (RATT): A prospective randomized study. World J Surg. 2014;38(6):1282-8.

19. Baek JH, Kim YS, Lee D, Huh JY, Lee JH. Benign predominantly solid thyroid nodules: Prospective study of efficacy of sonographically guided radiofrequency ablation versus control condition. Am J Roentgenol. 2010;194(4):1137-42.

20. Deandrea M, Limone P, Basso E, Mormile A, Ragazzoni F, Gamarra $E$, et al. US-Guided Percutaneous RadiofrequencyThermal Ablation for theTreatment of Solid Benign Hyperfunctioning or Compressive Thyroid Nodules. Ultrasound Med Biol. 2008; 34(5):784-91.

21. Jeong WK, Baek JH, Rhim H, Kim YS, Kwak MS, Jeong HJ, et al. Radiofrequency ablation of benign thyroid nodules: Safety and imaging follow-up in 236 patients. Eur Radiol. 2008;18(6):1244-50.

22. Owen RP, Silver CE, Ravikumar TS, Brook A, Bello J, Breining D. Techniques for Radiofrequency Ablation of Head and Neck Tumors. Arch Otolaryngol Head Neck Surg. 2004;130(1):52-6.

23. Baek JH, Moon WJ, Kim YS, Lee JH, Lee D. Radiofrequency ablation for the treatment of autonomously functioning thyroid nodules. World J Surg. 2009;33(9):1971-7.

24. Baek JH, Lee JH, Sung JY, Bae Jl, Kim KT, Sim J, et al. Complications encountered in the treatment of benign thyroid nodules with us-guided radiofrequency ablation: A multicenter study. Radiology. 2012;262(1):335-42.

25. Monzani F, Caraccio N, Goletti O, Lippolis PV, Casolaro A, Del Guerra $P$, et al. Five-year follow-up of percutaneous ethanol injection for the treatment of hyperfunctioning thyroid nodules: A study of 117 patients. Clin Endocrinol (Oxf). 1997;46(1):9-15.

26. Papini E, Guglielmi R, Bizzarri G, Graziano F, Bianchini A, Brufani $\mathrm{C}$, et al. Treatment of benign cold thyroid nodules: $\mathrm{A}$ randomized clinical trial of percutaneous laser ablation versus levothyroxine therapy or follow-up. Thyroid. 2007;17(3):229-35. 